\title{
An approach of clinical pharmacist pertaining to solve drug related problems in pediatric patients
}

\author{
S. Suwitha, Mohammed Fardan, Aswathy M. Shaji, Jimmer Joe, K. Hasif, \\ A. Priya, K. Arun Chander Yadav*
}

Department of Clinical Pharmacology, Apollo Children's Hospital, Chennai, Tamil Nadu, India

Received: 11 June 2020

Accepted: 09 July 2020

*Correspondence:

Dr. K. Arun Chander Yadav,

Email: clinicalpharmaach_cni@apollohospitals.com

Copyright: (c) the author(s), publisher and licensee Medip Academy. This is an open-access article distributed under the terms of the Creative Commons Attribution Non-Commercial License, which permits unrestricted non-commercial use, distribution, and reproduction in any medium, provided the original work is properly cited.

\begin{abstract}
Background: The objectives of the study were to assess the outcomes of clinical pharmacist intervention in solving drug related problems in pediatric patients and to identify the drug related problems in accordance with the causes observed.

Methods: It was a prospective observational study done over a period of six months (October 2019 to March 2020) at Apollo children's hospital in Chennai.

Results: Total of 480 subjects were enrolled into the study, out of which 248 were male children and 232 were female children. The patients were divided into 4 age groups. In this study $60.41 \%$ pediatric patients were prescribed with less than 5 drugs 290 (60.41\%). Drug related problems which were identified during the study was classified according to Pharmaceutical Care Network Europe (PCNE) and drug-related problem (DRP) classification (v9.00). The most frequent DRP was drug choice problem 37 (33.33\%). The total number of caused drug related problems was 73 and same number of interventions was given by clinical pharmacist. The most frequent cause of drug related problems was identified as dose selection 31 (42.46\%). Outcomes of interventions revealed that $70(95.89 \%)$ problems were solved overall.

Conclusions: In this study, clinical pharmacist's level of involvement has shown interesting results. Moreover, they play an essential role in improving patient safety and outcome, reducing cost and providing quality of care for ill patients.
\end{abstract}

Keywords: Drug related problems, Adverse drug reaction, Drug interactions, PCNE classification and pediatric patients

\section{INTRODUCTION}

Drug-related problems (DRPs) have been widely defined as any events or circumstances involving drug treatment that actually or potentially interfere with a patient experiencing optimal outcomes of medical care. ${ }^{1}$ The identification, prevention, and solution of DRPs, sometimes called medicine-related problems, are the essential attributable of pharmaceutical care. Any care activity to improve the use of medicines is designed to correct or prevent actual and potential DRPs, such as an adverse effect or interaction. ${ }^{2}$

DRP is a crucial term which comprises of medication errors and adverse drug reactions. Medication errors are very common in hospitals. ${ }^{3}$ Medication error is further subdivided into prescribing error, transcription error, dispensing error and administrative error. ${ }^{4}$ In whole, medication errors include wrong medication, wrong dose, wrong strength, wrong formulation, expired medication. ${ }^{5}$ 
While adverse drug reaction is defined as unintended response of drug when use in therapeutic dose. ${ }^{6}$ Intervention is defined as a step taken by pharmacist to optimize the therapeutic management in order to enhance the quality of patient care. Pharmacist plays a key role in minimizing DRP through proper use of medicines as most of the errors occur due to scarcity of drug information. $^{7}$

DRPs can be divided into intrinsic and extrinsic toxicity. Intrinsic toxicity is caused by the blending of the pharmaceutical, chemical and/or pharmacological characteristics of the drug itself and the human biosystem. Intrinsic toxicity is therefore synonymous with adverse drug reactions. ${ }^{8}$ A clinical pharmacist can play a very important role by addressing the whole range of drug therapy in hospitals and, in general, the clinical pharmacy services have been reported to improve patient care by reducing inappropriate prescribing, improve disease management, diminish adverse drug events, reduce length of stay, ADRs and mortality and result in economic benefit. ${ }^{9-13}$

\section{Pharmaceutical care network Europe classification for DRPs V9.00}

The classification mentioned herewith is for use in research and serves as an indispensable factor to nature, prevalence, and incidence of DRPs and also serves as a process indicator in experimental studies of Pharmaceutical Care outcomes. In addition, it also helps health care professionals in documenting DRPinformation in the pharmaceutical care processes. The word 'drug' is used throughout the classification, where others might use the term 'medicine'. Similar work in the field is evident in the hierarchical classification. In contrast, it differs from existing systems as it separates the drawbacks from the causes. Quality experts will recognize that most of the causes are often named 'medication errors' by others.

The official pharmaceutical care network Europe (PCNE)-DRP definition is the basis for the classification as mentioned below.

3 primary domains for problems have been identified for the basic classification now, 9 primary domains for causes and 5 primary domains for Interventions accordingly. However, on a more detailed level there are 7 grouped sub domains for problems, 43 grouped sub domains for causes and 17 grouped sub domains for interventions, and 10 sub domains for intervention acceptance. Those sub-domains can be seen as explanatory for the principal domains. In 2003, a scale has been added to indicate the extension of the problem that has been solved, containing 4 primary domains and 7 sub domains.

The aim of the study was to assess the outcomes of clinical pharmacist intervention in solving DRPs in pediatric patients; to identify the DRPs and their causes, importance of their interventions in solving DRPs. ${ }^{14}$

\section{Objectives}

The objectives of the study were to assess the outcomes of clinical pharmacist intervention in solving DRPs in pediatric patients and to identify the DRPs in accordance to the causes observed.

\section{METHODS}

Study design: Prospective observational study.

Study place: The study was conducted in Apollo children's hospital, in patient department, Tamil Nadu, which is an 80 bedded multispecialty child care hospital located in urban south India.

Study period: The duration of study was 6 months (October 2019 to March 2020).

Source of data: Patient data pertaining to study was obtained from patient case records.

Subject recruitment: The study method involves the selection of participants based on inclusion and exclusion criteria.

\section{Inclusion criteria}

Subject's age less than 12 years of both genders and subject's legal representatives who had signed the informed consent form were included.

\section{Exclusion criteria}

Subject's legal representative reluctant in joining the study were excluded.

\section{Study procedure}

The subjects were divided into four different age groups. A suitably designed data collection form was used to collect the necessary data including patient's gender, age and medication history. DRPs which were identified during the study were then classified according to PCNE DRP classification (v9.00).

\section{Statistical method}

A simple percentage calculation was conducted in order to derive conclusion out of the study. Microsoft word (2010) was used to generate tables, figures etc.

\section{RESULTS}

During the study period of 6 months, a total of 480 subjects were reviewed by clinical pharmacists. In our 
total study population $248(51.66 \%)$ cases were of male population and $232(48.33 \%)$ were female population (Figure 1).

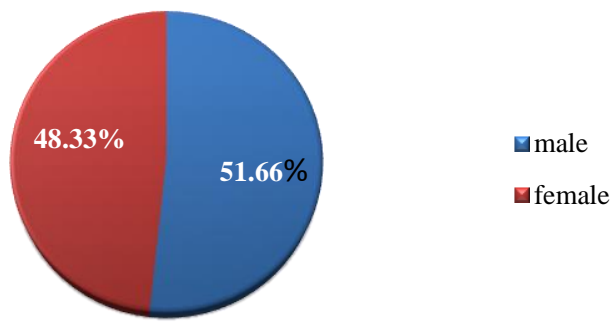

Figure 1: Gender wise distribution.

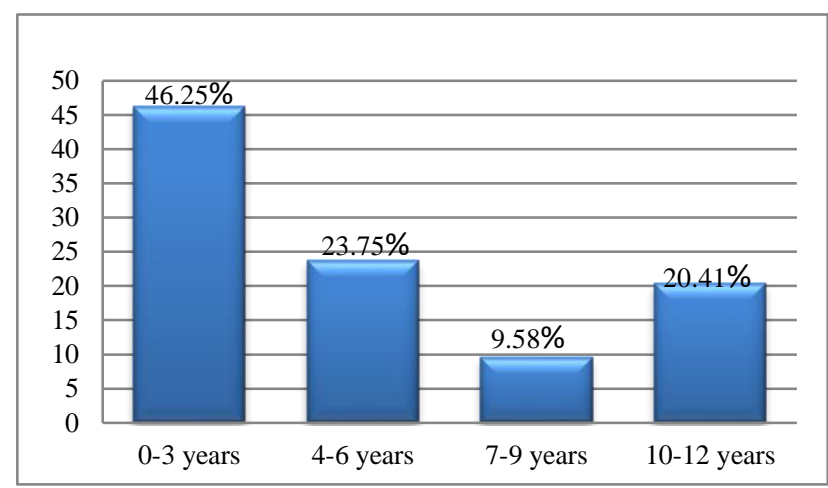

Figure 2: Age wise distribution.

Out of 480 pediatric patients, the maximum number of patients with age group between 0-3 years are 222 (46.25\%); followed by $114(23.75 \%)$ 4-6 years old; 46 (9.58\%) 7-9 years old and $98(20.41 \%)$ 10-12 years old (Figure 2).

Table 1: Number of drugs per prescription.

\begin{tabular}{|lll|}
\hline $\begin{array}{l}\text { Number of drugs } \\
\text { prescribed }\end{array}$ & $\begin{array}{l}\text { Number of } \\
\text { patients }\end{array}$ & $\begin{array}{l}\text { Percentage } \\
(\%)\end{array}$ \\
\hline$<\mathbf{5}$ & 290 & 60.41 \\
\hline $\mathbf{6 - 9}$ & 134 & 27.91 \\
\hline$>\mathbf{9}$ & 56 & 11.66 \\
\hline
\end{tabular}

In this study, $60.41 \%$ pediatric patients were prescribed with <5 drugs 290 (60.41\%), followed by 6-9 drugs 134 $(27.91 \%)$ and $>9$ drugs $56(11.66 \%)$ as shown in (Table 1).

Out of 480 pediatric patients were reviewed 111 subjects affected with DRPs. The most DRPs according to PCNE DRP (v9.00) were drug choice problem 37 (33.33\%), followed by $31(27.92 \%)$ dosing problem, $30(27.02 \%)$ drug interaction, $7(6.30 \%)$ drug use problem and 6 $(5.4 \%)$ adverse drug reactions. The interactions section constitutes mild, moderate as well as severe interactions (Table 2).

Table 2: DRP on PCNE classification.

\begin{tabular}{|lll|}
\hline DRP & $\begin{array}{l}\text { Number of } \\
\text { patients }\end{array}$ & $\begin{array}{l}\text { Percentage } \\
(\%)\end{array}$ \\
\hline Adverse drug reaction & 6 & 5.4 \\
\hline Drug choice problem & 37 & 33.33 \\
\hline Dosing problem & 31 & 27.92 \\
\hline Drug use problem & 7 & 6.30 \\
\hline Interactions & 30 & 27.02 \\
\hline Total & 111 & $100 \%$ \\
\hline
\end{tabular}

A total of 73 causes were identified during the study period. The most frequent cause of DRPs were identified as dose selection $31(42.46 \%)$ followed by dispensing 24 $(32.87 \%)$, drug selection $12(16.43 \%)$, patient related 3 $(4.10 \%)$, drug use process $2(2.7 \%)$ and drug form 1 $(1.36 \%)$ is shown (Table 3$)$.

The total numbers of caused DRPs were 73 and similar numbers of interventions were given by clinical pharmacist. All the interventions were classified according to PCNE DRP (v9.00). More interventions were proposed and resulted in acceptance by prescriber at drug level $31(42.46 \%) .30(41.09 \%)$ of interventions were provided at prescriber level, followed by $6(8.21 \%)$ of intervention were provided at patient level and same as other intervention level (Table 4).

Outcomes of interventions classifies according to PCNE DRP classification (v9.00) is shown in (Table 5). It reveals that $70(95.89 \%)$ of problems are totally solved and problems not solved $3(4.10 \%)$ respectively.

Table 3: Causes of DRP.

\begin{tabular}{|c|c|c|c|c|}
\hline S. no. & Causes of DRP & Number of causes & Total & Percentage $(\%)$ \\
\hline \multirow{5}{*}{1} & Drug selection & & \multirow{5}{*}{12} & \multirow{5}{*}{16.43} \\
\hline & Inappropriate drug & 1 & & \\
\hline & No indication of drug & 4 & & \\
\hline & Therapeutic duplication & 6 & & \\
\hline & Multiple drugs for indication & 1 & & \\
\hline \multirow{2}{*}{2} & Drug form & & \multirow[b]{2}{*}{1} & \multirow{2}{*}{1.36} \\
\hline & Inappropriate drug form & 1 & & \\
\hline
\end{tabular}

Continued. 


\begin{tabular}{|c|c|c|c|c|}
\hline S. no. & Causes of DRP & Number of causes & Total & Percentage $(\%)$ \\
\hline \multirow{8}{*}{3} & Dose selection & & \multirow{8}{*}{31} & \multirow{8}{*}{42.46} \\
\hline & High dose & 8 & & \\
\hline & Low dose & 13 & & \\
\hline & Wrong frequency & 6 & & \\
\hline & No therapeutic monitoring & 0 & & \\
\hline & Dose timing instruction use & 2 & & \\
\hline & Pharmacokinetic dose adjustment & 1 & & \\
\hline & Disease dose adjustment & 1 & & \\
\hline \multirow{4}{*}{4} & Dispensing & & \multirow{4}{*}{24} & \multirow{4}{*}{32.87} \\
\hline & Prescribed drug not available & 0 & & \\
\hline & Wrong strength, dosage advised & 22 & & \\
\hline & Dispensing error & 2 & & \\
\hline \multirow{5}{*}{5} & Drug use/ process & & \multirow{5}{*}{2} & \multirow{5}{*}{2.7} \\
\hline & Inappropriate dosing interval & 1 & & \\
\hline & Drug underused & 0 & & \\
\hline & Drugs overused & 1 & & \\
\hline & Drug abused & 0 & & \\
\hline \multirow{4}{*}{6} & Patient related & & \multirow{4}{*}{3} & \multirow{4}{*}{4.10} \\
\hline & Refused dose & 1 & & \\
\hline & Unnecessary use of drugs & 2 & & \\
\hline & Inappropriate storage & 0 & & \\
\hline
\end{tabular}

Table 4: Clinical pharmacist intervention for DRPs.

\begin{tabular}{|c|c|c|c|c|}
\hline S. no. & interventions & $\begin{array}{l}\text { Number of } \\
\text { interventions }\end{array}$ & Total & $\begin{array}{l}\text { Percentage } \\
(\%)\end{array}$ \\
\hline 1 & No intervention & 0 & 0 & 0 \\
\hline \multirow{5}{*}{2} & At prescriber level & & \multirow{5}{*}{30} & \multirow{5}{*}{41.09} \\
\hline & Prescriber informed only & 0 & & \\
\hline & Prescriber asked for information & 1 & & \\
\hline & Approved by prescriber & 28 & & \\
\hline & Not approved by prescriber & 1 & & \\
\hline \multirow{5}{*}{3} & At patient level & & \multirow{5}{*}{6} & \multirow{5}{*}{8.21} \\
\hline & Patient counseling & 2 & & \\
\hline & Written information provided only & 2 & & \\
\hline & Referred to prescriber & 0 & & \\
\hline & Spoken to family member & 2 & & \\
\hline \multirow{6}{*}{4} & At drug level & & \multirow{6}{*}{31} & \multirow{6}{*}{42.46} \\
\hline & Dosage change to & 20 & & \\
\hline & Formulation change to & 3 & & \\
\hline & Instruction for use & 2 & & \\
\hline & Drug stopped & 6 & & \\
\hline & New drug started & 0 & & \\
\hline \multirow{2}{*}{5} & Others & & \multirow{2}{*}{6} & \multirow{2}{*}{8.21} \\
\hline & Other intervention & 6 & & \\
\hline
\end{tabular}

Table 5: Outcomes of interventions.

\begin{tabular}{|c|c|c|c|c|c|}
\hline S. no. & Primary domains & Outcomes & $\begin{array}{l}\text { Number of } \\
\text { problems solved }\end{array}$ & Total & $\begin{array}{l}\text { Percentage } \\
(\%)\end{array}$ \\
\hline 1 & Problem status unknown & $\begin{array}{l}\text { Outcome interventions not } \\
\text { known }\end{array}$ & 0 & 0 & 0 \\
\hline 2 & Problems solved & Problem totally solved & 70 & 70 & 95.89 \\
\hline 3 & Problems partially solved & Problem partially solved & 0 & 0 & 0 \\
\hline \multirow{2}{*}{4} & \multirow{2}{*}{ Problems not solved } & $\begin{array}{l}\text { Not solved lack of cooperation } \\
\text { of patients }\end{array}$ & 2 & \multirow{2}{*}{3} & \multirow{2}{*}{4.10} \\
\hline & & $\begin{array}{l}\text { Lack of cooperation of } \\
\text { prescriber }\end{array}$ & 1 & & \\
\hline
\end{tabular}




\section{DISCUSSION}

Undoubtedly, clinical pharmacy services have made a positive impact on health care system. ${ }^{15}$ Clinical pharmacy activities have been shown to reduce the incidence of DRPs, hospitalization, hospital readmission and total cost of drug therapy. This study aims to assess the outcomes of clinical pharmacist intervention in solving DRPs in pediatric patients, to identify the DRPs and their causes, importance of their interventions in solving DRPs. PCNE DRP classification system (v9.00) was used in the study to identify various DRPs.

During the study period of 6 months, a total of 480 subjects were reviewed by clinical pharmacist. In our total study population, $248(51.66 \%)$ cases were male children and $232(48.33 \%)$ were female children. This could be due to the fact that more number of male children's visited the hospital in that particular period. This result matched with a study done by Ganachari et al. ${ }^{16}$ Out of 480 pediatric patients, the maximum number of patient age group between $0-3$ years $222(46.25 \%)$, Followed by $114(23.75 \%)$ were $4-6$ years old, $46(9.58 \%)$ were $7-9$ years old and $98(20.41 \%)$ were $10-12$ years old. The outcomes from this study though age factor was not considered with DRPs.

Out of 480 patients, total number of 111 DRPs were identified in this study and the common of the problems were associated to drug choice problem 37 (33.33\%), followed by $31(27.92 \%)$ dosing problem, $30(27.02 \%)$ drug interaction, $7(6.30 \%)$ drug use problem and 6 (5.4\%) adverse drug reactions. This result did not match with that of the study done by Muhammad Umair khan et al. ${ }^{17}$ Various causes identified in this study the major causes of these DRPs were dose selection $31(42.46 \%)$ followed by dispensing 24 (32.87\%), drug selection 12 $(16.43 \%)$, patient related $3(4.10 \%)$, drug use process 2 $(2.7 \%)$ and drug form $1(1.36 \%)$.

Of the total 73 DRPs identified, interventions were given for all the patients. More interventions were proposed and acceptance by prescriber at drug level 31 (42.46\%). 30 $(41.09 \%)$ of interventions were provided at prescriber level, followed by $6(8.21 \%)$ of intervention were provided at patient level and same as other intervention level. The reasons for the increased occurrence of DRPs could be increased workload of doctors/medicine PGs and lack of adequate knowledge especially about the newly marketed drugs, urgency in providing the treatment, and possible stress on health care professionals. Among the 70 (95.89\%) of problems solved and problems not solved 3 $(4.10 \%)$. This study indicates that clinical pharmacist intervention is important for solving DRPs in the pediatric patients. The overall observation made from this study was that clinical pharmacists have greater responsibility preventing and/or minimizing DRPs occurring in hospitals.

\section{CONCLUSION}

In this study, Clinical pharmacist's level of involvement has shown interesting results. We can conclude that almost $95.89 \%$ of interventions by this profession witnessed an indication of acceptance and recognition as active members of the healthcare team at Apollo children's Hospital. Moreover, clinical pharmacists play an essential role in improving patient safety and outcome, reducing cost and providing quality of care for ill patients.

\section{ACKNOWLEDGEMENTS}

Authors would like to express their immense gratitude towards Apollo Children's Hospital to permit and provide them with all the necessities required throughout the study period.

\section{Funding: No funding sources \\ Conflict of interest: None declared \\ Ethical approval: Not required}

\section{REFERENCES}

1. Covert KL, Mardis CR, Fleming JN, Pilch NA, Meadows HB, Mardis BA, et al. Development of a Predictive Model for Drug-Related Problems in Kidney Transplant Recipients. J Am Coll Clin Pharm. 2016;32(1):159-69.

2. Foppe van Mil JW, Westerlund LOT, Kurt E Hersberger, and Marion A Schaefer. Drug-Related Problem Classification System. ANN Pharmacother. 2004;38(5):859-67.

3. Brennan TA, Leape LL, Laird NM, Hebert L, Localio AR, Lawthers AG, et al. Incidence of adverse events and negligence in hospitalized patients. Results of the Harvard Medical Practice Study. IN Engl J Med. 1991;325(3):210.

4. Barber N, Rawlins M, Franklin BD. Reducing prescribing error: competence, control and culture. Qual Saf Health Care. 2003;12(Suppl 1):i29-i32.

5. Poon EG, Cina JL, Churchhill W, Patel N, Rothschild JM, Keohane CA, et al. Medication Dispensing Errors and Potential Adverse Drug Events before and after Implementing Bar Code Technology in the Pharmacy. Ann Intern Med. 2006;145(6):426-34.

6. Bates DW, Cullen DJ, Laird N, Petersen LA, Small $\mathrm{SD}$, Servi D, et al. Incidence of adverse drug events and potential adverse drug events: implications for prevention. JAMA 1995;274(1):29-34.

7. Mangasuli S, Rao Padma GM. Clinical intervention: A preliminary survey in a South Indian teaching hospital. Ind J Pharmacol. 2006;38(5):361-2.

8. PMLA van den Bemt, PhD Professor ACG Egberts. Drug-related problems: definitions and classification. EJHP Practice. 2007;13.

9. Bird JA, Lipton HL. The impact of clinical pharmacist's consultations on geriatric patient's compliance and medical care use: a randomized controlled trial. Gerontologist. 1994;34(3):307-15. 
10. Hanlon JT, Weinberger M, Samsa GP, Schmader KE. A randomized, controlled trial of a clinical pharmacist intervention to improve inappropriate prescribing in elderly outpatients with Polypharmacy. Am. J Med. 1996;100(4):428-37.

11. Abbott RD, Bogden PE, Koontz LM, Onopa JK, Williamson P. Comparing standard care with a physician and pharmacist team approach for uncontrolled hypertension. J Gen Intern Med. 1998;13(11):740-5.

12. Donovan JL, Drake JA, Tran MT, Whittaker P. Pharmacymanaged anticoagulation: assessment of inhospital efficacy and evaluation of financial impact and community Acceptance. J Thromb Thrombolysis. 2006; 22(1):23-30.

13. Allen KM, Bright J, Carey DL, Doecke CJ, Dooley MJ, Galbraith KJ, et al. Prospective multicentre study of pharmacist initiated changes to drug therapy and patient management in acute care government funded hospitals. Br J Clin Pharmacol. 2004;57(4):513-21.
14. PCNE Classification for Drug-Related Problems V9.00.

15. Rasmussen M, Struck PA. Pilot study of pharmacist initiated interventions in drug therapy in an Australian pediatric hospital. EJHP. 2007;13:105-12.

16. Ganachari MS, Mahendra Kumar BJ, Wali SC, Fibin M. Assessment of Drug Therapy Interventions by Clinical Pharmacist in a Tertiary Care Hospital. Ind J Pharm Pract. 2010;3:22-8.

17. Muhammad Umair Khan, Akram Ahmad, The Impact of Clinical Pharmacists' Interventions on Drug Related Problems in a Teaching Based Hospital. Int J Pharm Clin Res. 2014;6(3):276-280.

Cite this article as: Suwitha S, Fardan M, Shaji AM, Joe J, Hasif K, Priya A, et al. An approach of clinical pharmacist pertaining to solve drug related problems in pediatric patients. Int J Basic Clin Pharmacol 2020;9:1263-8. 